\title{
Publisher Correction: Interplay between hypoxia and androgen controls a metabolic switch conferring resistance to androgen/AR-targeted therapy
}

Hao Geng ${ }^{1}$, Changhui Xue ${ }^{1}$, Janet Mendonca ${ }^{2}$, Xiao-Xin Sun ${ }^{3}$, Qiong Liu' ${ }^{1}$, Patrick N. Reardon (10 ${ }^{4}$, Yingxiao Chen ${ }^{3}$, Kendrick Qian1, Vivian Hua', Alice Chen¹, Freddy Pan', Julia Yuan1, Sang Dang1, Tomasz M. Beer (1) 1,5, Mu-Shui Dai ${ }^{3}$, Sushant K. Kachhap ${ }^{2}$ \& David Z. Qian ${ }^{1,5}$

Correction to: Nature Communications (2018) 9:4972; https://doi.org/10.1038/s41467-018-07411-7; published online 26 November 2018

The original version of this Article contained errors in Fig. 7. In panels e and f, the graph titles incorrectly read 'LNCaP-AdtNs' and 'LAPC4-AdtNs', respectively. These errors have now been corrected in both the PDF and HTML versions of the Article.

Published online: 08 January 2019

\footnotetext{
(c) (i) Open Access This article is licensed under a Creative Commons Attribution 4.0 International License, which permits use, sharing, adaptation, distribution and reproduction in any medium or format, as long as you give appropriate credit to the original author(s) and the source, provide a link to the Creative Commons license, and indicate if changes were made. The images or other third party material in this article are included in the article's Creative Commons license, unless indicated otherwise in a credit line to the material. If material is not included in the article's Creative Commons license and your intended use is not permitted by statutory regulation or exceeds the permitted use, you will need to obtain permission directly from the copyright holder. To view a copy of this license, visit http://creativecommons.org/licenses/by/4.0/.
}

(c) The Author(s) 2019

\footnotetext{
${ }^{1}$ OHSU Knight Cancer Institute, Prostate Cancer Program, Oregon Health \& Science University, 3181 SW Sam Jackson Park Road, Portland, OR 97239, USA

2 Johns Hopkins Kimmel Cancer Center, 401 N Broadway, Baltimore, MD 21287, USA. ${ }^{3}$ Department of Medical Genetics, Oregon Health \& Science University, 3181 SW Sam Jackson Park Road, Portland, OR 97239, USA. ${ }^{4}$ NMR Core facility, Oregon State University, Corvallis, OR 97331, USA. ${ }^{5}$ Division of Hematology \& Medical Oncology, Oregon Health \& Science University, 3181 SW Sam Jackson Park Road, Portland, OR 97239, USA. These authors contributed equally: Hao Geng, Changhui Xue, Janet Mendonca. The original article can be found online at https://doi.org/10.1038/s41467-018-07411-7. Correspondence and requests for materials should be addressed to D.Z.Q. (email: qianzh@ohsu.edu)
} 